ШИРОКОВА Олеся Вадимовна - кандидат социологических наук, доцент Института государственной службы и управления Российской академии народного хозяйства и государственной службы при Президенте РФ (119571, Россия, г. Москва, np-кm Вернадского, 82; ov.shirokova@igsu.ru) МАХНИЦКИЙ Данил Павлович - аспирант Института государственной службы и управления Российской академии народного хозяйства и государственной службы при Президенте РФ (119571, Россия, г. Москва, пр-кт Вернадского, 82; d.makhn@уа.ru)

\title{
ИСПОЛЬЗОВАНИЕ ТРАНСАКЦИОННОГО ПОДХОДА ДЛЯ ОЦЕНКИ ЭФФЕКТИВНОСТИ ОРГАНИЗАЦИИ ПРОЦЕССОВ В СИСТЕМЕ ГОСУДАРСТВЕННОГО УПРАВЛЕНИЯ РОССИЙСКОЙ ФЕДЕРАЦИИ
}

\begin{abstract}
Аннотация. Цифровая модернизация - один из текущих стратегических приоритетов системы государственного управления Российской Федерации. В рамках данной статьи авторы доказывают наличие двух серьезных методологических пробелов при организации процесса цифровой модернизации государственного управления. В целях методологической корректировки этих процессов авторы предлагают ввести в социологию управления понятие «трансакционный подход». Этот методологический инструмент является универсальным и может использоваться как для оценки эффективности цифровой модернизации отдельного ведомства, так и для аудита эффективности организации процессов на государственной гражданской службе в целом.

Ключевые слова: цифровизация государственного управления, цифровая модернизация, эффективность государственного управления, трансакционный подход, теория трансакционных издержек, централизация обеспечивающего функционала
\end{abstract}

$\mathrm{B}$ настоящий момент правительство РФ активно ведет работу по цифровой модернизации отраслей экономики и государственного управления в рамках национального проекта «Цифровая экономика Российской Федерации». На цифровизацию экономики и внедрение цифровых инструментов заложено больше 1,6 трлн руб. бюджетных и внебюджетных расходов до 2024 г. ${ }^{1}$

Цифровизация государственного управления - общемировая тенденция, что подтверждается исследованиями наднациональных организаций. К примеру, $\mathrm{OOH}$ рассчитывает собственный Индекс развития цифрового правительства (E-Government Development Index) уже больше 20 лет. По данным последней оценки, проведенной в 2020 г., Российская Федерация занимала в данном рейтинге 36 -е место 2 .

Одной из существенных частей общей цифровизации экономики является цифровая модернизация государственного управления [Добролюбова, Южаков, Старостина 2021: 7]. Стоит отметить, что признанных государственным аппаратом, экспертами и научным сообществом критериев оценки эффективности цифровой модернизации в России пока выработано не было [Добролюбова, Южаков, Старостина 2021: 10].

1 Национальный проект. Цифровая экономика. Доступ: http://static.government.ru/ media/files/3b1AsVA1v3VziZip5VzAY8RTcLEbdCct.pdf (проверено 11.07.2021).

2 Исследование ООН: Электронное правительство 2020. Цифровое правительство в десятилетии действий по достижению устойчивого развития. Доступ: https:// publicadministration.un.org/egovkb/Portals/egovkb/Documents/un/2020-Survey/2020\%20 UN\%20E-Government\%20Survey\%20-\%20Russian.pdf (проверено 13.07.2021). 
Отсутствие комплексных и универсальных критериев оценки эффективности процесса цифровой модернизации неизбежно приводит к фрагментарному выхолащиванию целей цифровой трансформации. Уже сейчас исследователи выделяют существенные риски того, что в условиях отсутствия конечных критериев оценки эффективности цифровая трансформация государственного аппарата может стать самоцелью и ограничится лишь точечными изменениями в процессуальной, а не сутевой части организации работы ведомств, в то время как реальная цель цифровой трансформации государственного аппарата - изменение структуры взаимоотношений с внешними акторами: гражданами и бизнесом [Добролюбова и др. 2019: 5].

При этом само экспертное сообщество, вовлеченное в процесс трансформации, выделяет несколько крупных блоков проблем в данной отрасли:

1) низкая степень подготовленности государственных служащих к процессам цифровой трансформации и их заинтересованности;

2) недостаточная степень координации и межведомственной согласованности как при выборе целевых ориентиров, так и при подборе конкретных инструментов цифровизации;

3) устаревший корпус законодательства, регулирующий процессы цифровизации и работы с данными.

Наличие этих проблем подтверждает и сам министр цифрового развития, связи и массовых коммуникаций РФ Максут Шадаев ${ }^{1}$ в интервью отраслевому порталу TAdviser.

В условиях кратного увеличения объема федеральных полномочий, вопрос эффективности организации процессов и процедур внутри госаппарата приобретает критическое значение. Так, к концу 2016 г. федеральные органы исполнительной власти реализовывали около 10450 полномочий, что практически в 2 раза больше, чем в 2003 г. [Кнутов, Синятуллина 2018: 118]. А ведь каждое полномочие состоит из десятков, а то и сотен функциональных процессов и процедур.

Говоря о необходимости цифровой модернизации государственного аппарата и выработки теоретических подходов для этой модернизации, мы в существенной степени опираемся на институциональный подход Дугласа Норта [Лебедев 2011: 58]. Знакомство с предложенным Д. Нортом алгоритмом институционных изменений позволяет сделать вывод, что новые знания и технологии рано или поздно запускают процесс не только экономических, но и социально-политических изменений в обществе. Ситуация осложняется тем, что процессы институциональных изменений затрагивают не только экономические интересы, но и идеологические убеждения как отдельных людей, так и больших социальных групп [Матвеев 2017: 48].

При этом стоит выделить ряд общественно-политических факторов, которые на сегодняшний день вынуждают систему государственного управления выбрать путь «эволюционных» институциональных изменений, по Д. Норту:

1) изменение структуры трудовых и мотивационных предпочтений граждан на фоне пандемии COVID-19 и вынужденной цифровизации многих операционных процессов;

2) массовый запрос граждан на упрощение взаимодействия с государственными органами и использование цифровых инструментов при организации двусторонней коммуникации;

1 Интервью TAdviser: Глава Минцифры Максут Шадаев - о новых подходах к цифровизации государства. - Министерство иифрового развития, связи и массовых коммуникаций Российской Федерации. 10.09.2021. Доступ: https://digital.gov.ru/ru/ events/41257/ (проверено 05.10.2021). 
3) цифровизация организации труда, расширение числа удаленных вакансий и последующее усиление международной конкуренции за кадры;

4) массовый выход на рынок высококвалифицированного труда представителей постсоветских поколений.

Наряду с экономическим контекстом, развитие идей Дугласа Норта распространилось и на решение проблем других гуманитарных дисциплин. Нас же в данном случае особенно интересует теория трансакционных издержек, сформулированная О. Уильямсоном в развитие идей Д. Норта.

И это не случайно. В неоинституциональном анализе трансакционные издержки - базовое понятие, посредством которого объясняются и экономические, и политические, и социальные процессы.

Первоначально трансакционные издержки были определены как «издержки пользования рыночным механизмом». Позднее это понятие приобрело более широкий смысл. Оно стало обозначать любые виды издержек, сопровождающих взаимодействие экономических агентов независимо от того, где оно протекает - на рынке или внутри организаций. Выделяют разные категории трансакций - трансакции управления, рационирования, поиска информации, ведения переговоров и др.

При этом Д. Норт считал, что главная задача социальных институтов - минимизация трансакционных издержек. Эволюционный процесс любой системы, как он утверждал, неизбежно приводит к последовательной замене неэффективных институтов более эффективными, что, в конечном итоге, приводит к снижению трансакционных издержек [Гульбина 2004: 125]. Под институтами Д. Норт подразумевал устойчивую совокупность формальных и неформальных правил, уменьшающих неопределенность путем установления общих правил взаимодействия. При этом Д. Норт писал, что у такого института, как государство, есть две диаметрально противоположные установки в отношении эволюционного процесса. Первая трактовка стандартна - эволюция приводит к установлению несколько более эффективного порядка, нежели ранее. А вот вторая установка, наоборот, приводит к стремительному расширению функций и полномочий государства без особой оглядки на эффективность внутренних трансакций и влияния этого процесса на темпы развития национальной экономики.

Задачей теории трансакционных издержек является объяснение проблем эффективности тех или иных экономических операций в определенных институциональных рамках, т.е. способность различных организационных форм результативно планировать и осуществлять хозяйственные цели.

При этом отечественные исследователи отмечают, что само по себе измерение трансакционных издержек на макроуровне не дает существенного приращения научного знания. Полученные данные слабо применимы на практике, не дают целевых ориентиров для субъектов хозяйственного процесса и в целом носят скорее формальный статистический характер [Нечаев 2015: 174]. А вот использование трансакционного подхода для анализа на мезо- и микроуровне (уровень отдельных субъектов) признается перспективным направлением для изучения.

Поэтому в рамках данной статьи мы вводим в научный социологический оборот понятие «трансакционный подход» и предлагаем использовать данное понятие не только применительно к цифровой модернизации госуправления, но и к организации управленческой деятельности на государственной гражданской службе в целом. Ведь само по себе внедрение цифровых инструментов не решит проблем государственного управления без глубокого переосмысления принципов организации работы [Цифровая трансформация... 2019: 17].

Трансакционный подход обосновывает необходимость учета при реформи- 
ровании государственного аппарата ключевого принципа декомпозиции из кибернетики. В частности, принцип декомпозиции гласит, что управляемый объект (в нашем случае это государственная гражданская служба в целом) является совокупностью независимых подсистем разного уровня и масштаба.

Логично, что в соответствии с этим же принципом работу каждой из изучаемых подсистем можно представить в виде совокупности отдельных технологических процессов. Процессов, каждый из которых состоит из сотен рутинных организационных действий: звонков, официальных писем, согласований, отзывов на проект документа и т.д.

Сама структура любого процесса позволяет нам декомпозировать каждый из них уже на отдельные неделимые элементы ведомственной работы и ввести дополнительное понятие «бюрократические трансакции». Отдельная трансакция - это всегда законченное действие, формализующееся на этапе перехода от заключительной точки одного технологического процесса к началу другого. При этом в зависимости от масштаба процесса меняется и масштаб трансакции.

Если речь идет о межведомственном взаимодействии и мы рассматриваем, к примеру, процесс согласования проекта федерального нормативного правового акта, то в качестве трансакции можно обозначить весь контур внутренней работы над проектом в рамках одного ведомства. В таком случае начнется трансакция в момент поступления проекта акта в ведомство, а закончится в момент отправки отзыва на проект акта в другой государственный орган.

При этом мы может рассмотреть тот же процесс с точки зрения процесса подготовки позиции отдельным ведомством, и тогда одной трансакцией будет предоставление позиции на проект акта обособленным отделом. Таким образом, глубину выделения трансакции определяет сам субъект исследования, отталкиваясь от изначальной аналитической задачи.

Схематически, опираясь на системный подход, процесс выделения отдельной трансакции в зависимости от фокуса субъекта осуществления этого процесса можно описать в соответствии со схемой, приведенной на рис. 1.

Каждая такая трансакция имеет определенный технологический, организационный и социальный контекст. Кто осуществляет трансакцию, на основании какого регламентирующего документа и что исполнитель трансакции ожидает получить от ее реализации - без ответа на эти вопросы оптимизация, а уж тем более цифровизация отдельного операционного процесса не возымеет ожидаемого эффекта.

В силу отсутствия теоретической базы нынешний подход ведомств к цифровой модернизации не учитывает и другой базовой установки кибернетики - принципа эмерджентности, а внедрение отдельных цифровых инструментов становится управленческой самоцелью. Возникает дисфункция государственного управления, которая может породить проявления структурной аномии социального института в целом.

Принцип эмерджентности гласит, что локальные цели отдельных элементов системы могут не совпадать с верхнеуровневыми целями и задачами системы в целом. Отталкиваясь от этого принципа, субъекту внедрения изменений при выработке стратегических ориентиров важно брать во внимание возможность «преломления» целевых установок отдельными субъектами хозяйственной деятельности.

Отчасти именно из-за этой методологической недоработки прямо сейчас государственный аппарат упускает возможность существенной внутренней организационной и процессуальной модернизации. При этом опыт отечественных госкорпораций ярко свидетельствует, что этап широ- 


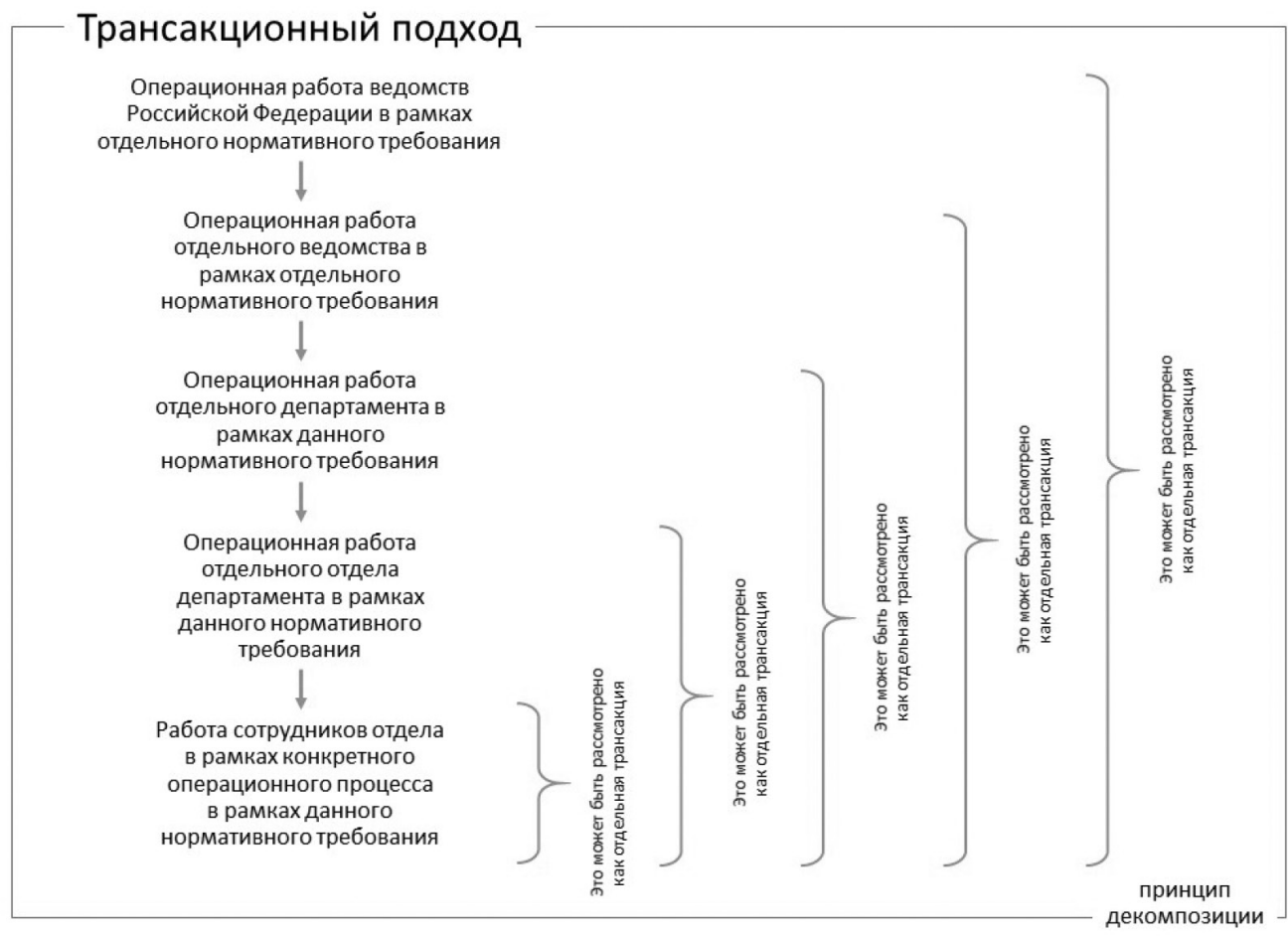

Рисунок 1. Зависимость объема выделяемой трансакции от целей и задач субъекта изучения организации

кого внедрения цифровых инструментов может стать отправной точкой для полноценной организационной модернизации и формирования новой организационной культуры [Ответ на вызовы... 2020: 14].

Важно отметить, что гибкость трансакционного подхода позволяет ему быть универсальным инструментом для оценки модернизации тех или иных процессов в иерархичных системах. Трансакционный подход в равной степени эффективности позволяет оценить как трудозатраты конкретных сотрудников одного отдела, так и трудозатраты в целом в пересчете на отдельное ведомство. Он позволяет формировать сводные показатели и оценивать потенциальные временные затраты при формировании дополнительных регуляторных требований и государственных функций и в целом выстроить работу по преобразованию процессов в соответствии с принципом эмерджентности.

Трансакционный подход может стать серьезным методологическим подспорьем в ходе неизбежной будущей централизации обеспечивающих процессов федеральных ведомств исполнительной власти. Стоит отметить, что подобная централизация уже была успешно проведена большинством крупных отечественных организаций, таких как ПАО «ГМК «Норильский никель», ПАО «Северсталь», ПАО «РЖД», ПАО «Банк ВТБ», ПАО «Сбербанк» и др.

Трансакционный подход также может стать сильным аргументом в пользу «регуляторной гильотины», речь о которой в экспертной и профессиональной среде ведется давно. Подсчет трудозатрат с использованием трансакционного подхода также может стать серьезным политическим аргументом для снижения бюрократической нагрузки 
на предпринимателей, а также на представителей всех профессий бюджетного сектора.

Логично, что теоретическая модель трансакционного подхода неизбежно рождает прикладную модель трансакционной модернизации государственного аппарата - модель, которая дает понятную последовательность организационных действий по преобразованию повседневной деятельности ведомств и при этом не нарушает ни один из законов и принципов кибернетики. Конфигурация этой модели, а также последовательность действий по ее применению на практике являются предметом отдельного исследования.

Таким образом, можно однозначно говорить, что существующая практическая деятельность по цифровизации государственного аппарата без соответствующей теоретической модели приводит к выхолащиванию самой идеи цифровизации. Цифровая модернизация государственного аппарата не может быть осуществлена частично или фрагментарно. Только последовательный и пошаговый подход позволит максимизировать полезные эффекты от внедрения новых цифровых инструментов.

Для того чтобы создать систему оценки эффективности любого модернизационного процесса в рамках системы государственного управления, мы и вводим понятие трансакционного подхода. При должной теоретической проработке трансакционный подход может стать универсальной методологической базой оценки эффективности деятельности любых систем, подсистем, процессов и отдельных технологических этапов в рамках системы государственного управления.

Подводя итоги данной части нашего исследования, можно сделать следующие выводы.

1. В настоящий момент цифровая трансформация - один из государственных приоритетов. На данный процесс выделяются существенные бюджетные средства, и по многим показателям Российская Федерация показывает динамику выше средней по миру.

2. Отсутствие исчерпывающей методологической базы цифровизации государственного управления приводит к целому ряду системных проблем и недоработок - темпы цифровизации замедляются, размываются цели и задачи цифровизации, весомая часть работы ведется ради отчетности.

3. В поисках методологического базиса процесса цифровизации исследователям стоит обратиться к институциональному подходу Д. Норта и теории трансакционных издержек, сформулированной О. Уильямсоном, а также ввести в научный оборот социологии управления понятие «трансакционный подход».

4. Существующий подход к цифровизации государственного управления нарушает принцип декомпозиции и эмерджентности, что приводит к фундаментальным управленческим ошибкам и перерасходу затрачиваемых ресурсов.

5. Трансакционный подход может лечь в основу процесса масштабной централизации обеспечивающего функционала федеральных органов исполнительной власти.

\section{Список литературы}

Гульбина Н.И. 2004. Теория институциональных изменений Д. Норта. Вестник Томского государственного университета. № 283. С. 123-128.

Добролюбова Е.И., Южаков В.Н., Старостина А.Н. 2021. Цифровая трансформация государственного управления: оценка результативности и эффективности. М.: ИД «Дело» РАНХиГС. 234 с.

Добролюбова Е.И., Южаков В.Н., Ефремов А.А., Клочкова Е.Н., 
Талапина Э.В., Старцев Я.Ю. 2019. Цифровое будущее государственного управления по результатам. М.: ИД «Дело» РАНХиГС. 114 с.

Кнутов А.В., Синятуллина Л.Х. 2018. Полномочия федеральных органов исполнительной власти: количественный анализ и классификация. - Bonpocы государственного и муниципального управления. № 1. С. 109-125.

Лебедев Д.С. 2011. Трансакционно-сетевой подход к оценке институциональных изменений. - Проблемы современной экономики. № 4. С. 58-63.

Матвеев В.В. 2017. Теория институциональных изменений Дугласа Норта: обоснование стратегической роли знаний в обеспечении эффективного развития общества. - Вестник Удмуртского университета. Сер. Экономика и право. № 5(27). C. 48-54.

Нечаев А.Д. 2015. Макроэкономический подход к измерению трансакционных издержек. - Инновации в науке. № 2(39). С. 172-178.

Ответ на вызовы цифровизации: госуправление, основанное на данных, «штабная» модель управления и структурный маневр в численности госслужащих: доклад НИУ ВШЭ (рук. авт. кол. А.Б. Жулин, Я.И. Кузьминов). 2020. М.: ИД ВШЭ. 45 с.

Цифровая трансформация государственного управления: мифы и реальность: доклад к международной научной конференции по проблемам развития экономики и общества. Москва, 9-12 апреля 2019 г. (под общ. ред. Н.Е. Дмитриевой). 2019. М.: ИД ВШЭ. 43 с.

SHIROKOVA Olesja Vadimovna, Cand.Sci. (Soc.), Associate Professor at the Institute of Public Service and Management, Russian Presidential Academy of National Economy and Public Administration (RANEPA) (82 Vernadskogo Ave, Moscow, Russia,119571; ov.shirokova@igsu.ru)

MAHNICKIJ Danil Pavlovich, postgraduate student at the Institute of Public Service and Management, Russian Presidential Academy of National Economy and Public Administration (RANEPA) (82 Vernadskogo Ave, Moscow, Russia, 119571;d.makhn@ya.ru)

\section{USAGE OF A TRANSACTIONAL APPROACH TO ASSESS THE EFFECTIVENESS OF THE ORGANIZATION OF PROCESSES IN THE PUBLIC ADMINISTRATION SYSTEM OF THE RUSSIAN FEDERATION}

Abstract. Digital modernization is one of the current strategic priorities of the public administration system of the Russian Federation. The authors prove the existence of two serious methodological gaps in the organization of the process of digital modernization of public administration. They propose to introduce the concept of transactional approach into the sociology of management in order to correct these processes methodologically. This methodological tool is universal and can be used both to rate the effectiveness of digital modernization of a separate department, and to audit the effectiveness of the organization of processes in the public civil service as a whole. The transactional approach developed by the authors can not only form the basis for the development of a practical model for evaluating the implementation efficiency or modernization of separate public administration processes, but also form the basis for launching the large-scale centralization process for providing functionality of federal executive bodies.

Keywords: digitalization of public administration, digital modernization, efficiency of public administration, transaction approach, theory of transaction costs, centralization of providing functionality 